\title{
(6) OPEN ACCESS \\ Antidoping programme and biological monitoring before and during the 2014 FIFA World Cup Brazil
}

\author{
Norbert Baume, ${ }^{1}$ Nicolas Jan, ${ }^{1}$ Caroline Emery, ${ }^{1}$ Béatrice Mandanis, ${ }^{1}$ \\ Carine Schweizer, ${ }^{1}$ Sylvain Giraud, ${ }^{1}$ Nicolas Leuenberger, ${ }^{1}$ François Marclay, ${ }^{1}$ \\ Raul Nicoli, ${ }^{1}$ Laurent Perrenoud, ${ }^{1}$ Neil Robinson, ${ }^{1}$ Jiri Dvorak, $^{2,3^{3}}$ Martial Saugy ${ }^{1}$
}

${ }^{1}$ Swiss Laboratory for Doping Analyses, University Center of Legal Medicine, Geneva \& Lausanne, Epalinges, Switzerland

${ }^{2}$ FIFA, Zürich, Switzerland ${ }^{3}$ FIFA Medical Assessment and Research Centre (F-MARC) and Schulthess Clinic, Zürich, Switzerland

Correspondence to Dr Norbert Baume, Swiss Laboratory for Doping Analyses, University Center of Legal Medicine, Geneva \& Lausanne, Chemin des Croisettes 22, Epalinges 1066, Switzerland;

norbert.baume@chuv.ch

Accepted 4 March 2015

\section{ABSTRACT}

Background The FIFA has implemented an important antidoping programme for the 2014 FIFA World Cup.

Aim To perform the analyses before and during the World Cup with biological monitoring of blood and urine samples.

Methods All qualified players from the 32 teams participating in the World Cup were tested out-ofcompetition. During the World Cup, 2-8 players per match were tested. Over 1000 samples were collected in total and analysed in the WADA accredited Laboratory of Lausanne.

Results The quality of the analyses was at the required level as described in the WADA technical documents. The urinary steroid profiles of the players were stable and consistent with previously published papers on football players. During the competition, amphetamine was detected in a sample collected on a player who had a therapeutic use exemption for attention deficit hyperactivity disorder. The blood passport data showed no significant difference in haemoglobin values between out-of-competition and postmatch samples.

Conclusions Logistical issues linked to biological samples collection, and the overseas shipment during the World Cup did not impair the quality of the analyses, especially when used as the biological passport of football players.

\section{INTRODUCTION}

The Fédération Internationale de Football Association (FIFA) introduced doping controls in 1966 to ensure a fair competition prior and during the FIFA World Cup tournaments. ${ }^{1}$ The doping controls of the 2014 FIFA World Cup in Brazil were managed by the FIFA Medical Office and the FIFA Sports Medical Committee, as done for all the previous World Cups. Antidoping procedures were applied in accordance with the FIFA antidoping regulations and the respective WADA International Standards. ${ }^{2} 3$ Prior to the World Cup finals, an extensive campaign of out-of-competition (OOC) antidoping tests was organised to collect blood and urine samples from individual players from the 32 qualified countries, corresponding to a total of more than 750 OOC samples. ${ }^{4}$ This collection was the first step to implement the athlete biological passport (ABP), a new strategy in football. ${ }^{5-8}$ During the 64 matches played in Brazil, a further 300 blood and urine samples were collected in competition (IC). The real effect on the blood values for the biological passport obtained after a football game has not been really investigated until now.
This study aimed to compare the results of the analyses for several key biological parameters obtained in the OOC and the IC phases. This will preview the application of the biological passport in football. In addition, we aimed to provide a global picture of the antidoping analyses results in football.

\section{METHODS}

\section{Samples collection}

For the OOC testing programme, 32 teams were tested during their training camp period, which extended from 3 March to 6 June 2014. In total, 779 urine samples, 769 whole blood samples (EDTA) and 773 serum samples were collected during the OOC. All sampling procedures were performed unannounced by a team of specially trained doctors and nurses according to the location of the teams. Samples from one team were grouped into a single parcel and sent to the laboratory, either by courier or delivered by hand under controlled temperature conditions as defined in the applicable regulations. ${ }^{2}$ During this precompetition phase, most of the samples were collected during training camps in the following countries: Austria, Belgium, France, Greece, Italy, the Netherlands, Norway, Portugal, Spain, Switzerland, the UK, Argentina, Brazil, Chile, Costa Rica, Mexico, the USA and Uruguay (figure 1).

FIFA World Cup 2014 took place in Brazil, from 12 June to 13 July, in 12 different venues (figure 2).

In total, 300 urine samples, 305 EDTA and 307 serum samples were taken in the IC period of 64 matches. Each football game corresponded to one bundle was delivered to the Laboratory of Lausanne.

\section{Sample delivery}

To ensure fair competition during the tournament, results for tests were produced before the next match for each team. To achieve this, the transportation schedule was prepared in advance by the staff of the FIFA Medical Office. The local organising committee in Brazil coordinated with courier companies to ensure transportation conditions for the samples as described by the International Standard for Testing inside Brazil and overseas. Samples were kept at a refrigerated temperature between the collection sites and the laboratory. The delivery time for the shipments during the competition is described in the figure 3 and table 1 . All samples arrived at the laboratory in less than $48 \mathrm{~h}$, 


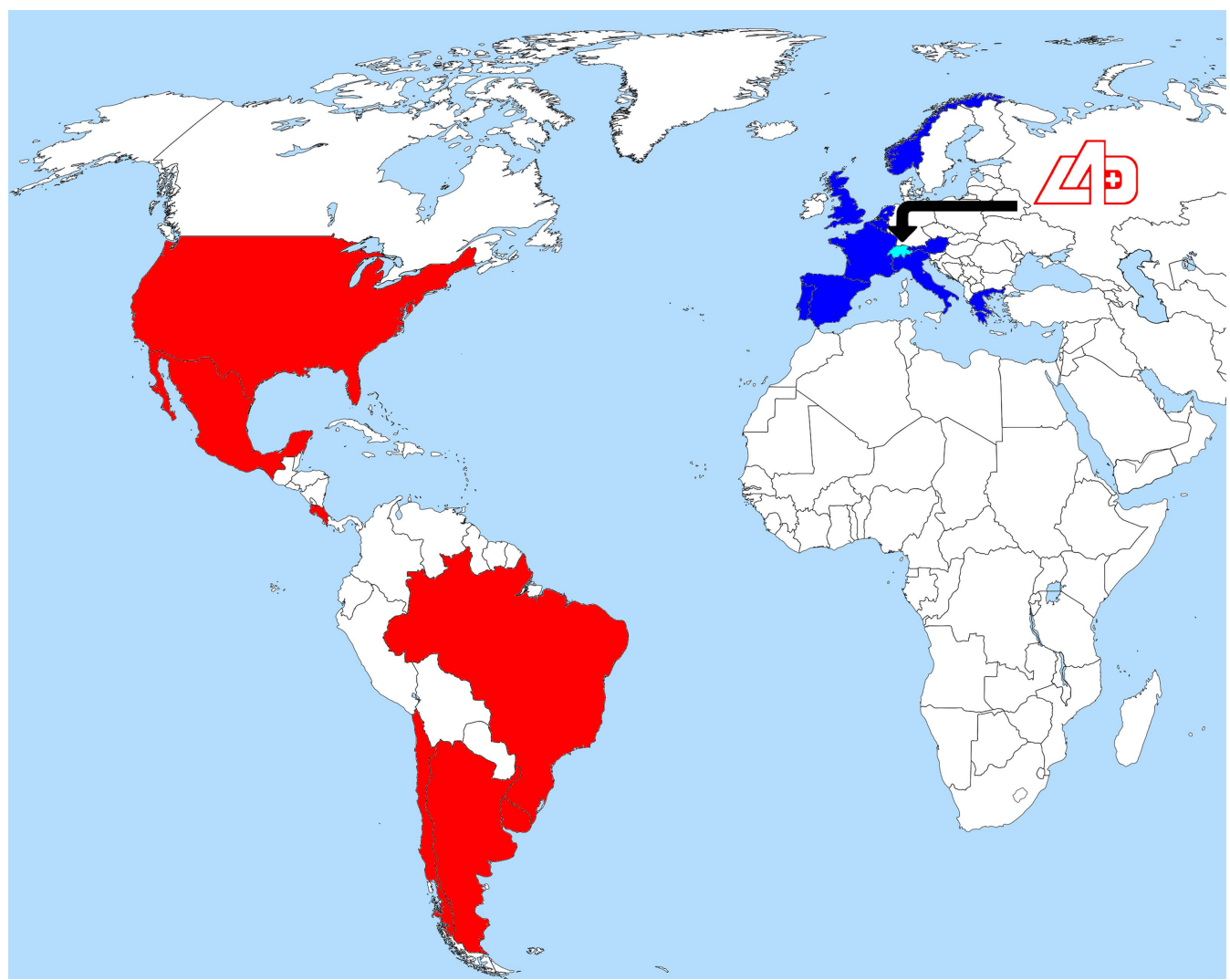

Figure 1 Map of countries where out-of-competition samples were collected and geographical position of the Swiss Laboratory for Doping Analyses (LAD). In Europe: Austria, Belgium, France, Greece, Italy, the Netherlands, Norway, Portugal, Spain and Switzerland. In Americas: Argentina, Brazil, Chile, Costa Rica, Mexico, the USA and Uruguay.

allowing the whole blood samples to be analysed in time as described in the WADA guidelines.

In table 1 , the analyses turnaround time is shown. The mean time for both urine and serum analytical reports to the FIFA Medical Office were made in less than 24 and $31 \mathrm{~h}$, respectively. In these conditions, all results were reported in due time, prior to the next game for each participant in the competition. Temperatures of blood and serum samples were measured on



Figure 2 The 12 venues in Brazil for the 2014 FIFA World Cup. the arrival in the laboratory and these met the international standards for testing. Samples were transported under appropriate refrigerated conditions.

\section{Sample analysis}

All urine samples were analysed with the established and accredited antidoping analytical methods. Quantification of the steroid profile was performed on a Hewlett Packard 6890 GC system plus gas chromatography system coupled to a Hewlett Packard 5973 Mass Selective Detector (Palo Alto, California, USA) mass spectrometer. Screening analyses for the detection of anabolic steroids (class S1) were performed on an Agilent 7890B gas chromatography system coupled to a Triple Quadrupole 7000B (Wilmington, Delaware, USA). Both instruments were

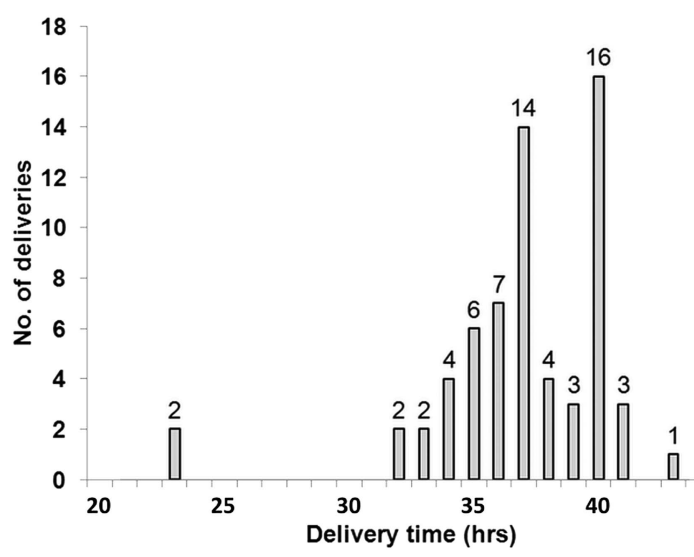

Figure 3 Delivery time of samples from the 12 venues to the laboratory during the 2014 FIFA World Cup. 
Table 1 Delivery times and temperatures of refrigerated boxes at reception to the laboratory during the IC phase.

\begin{tabular}{lllll} 
& $\begin{array}{l}\text { Delivery } \\
\text { time }(\mathrm{h})\end{array}$ & $\begin{array}{l}\text { Temperature } \\
\text { at reception }\left({ }^{\circ} \mathrm{C}\right)\end{array}$ & Urine & Serum \\
\hline Mean & $38 \mathrm{~h} 11 \mathrm{~min}$ & 7.7 & $23 \mathrm{~h} \mathrm{39min}$ & $30 \mathrm{~h} \mathrm{21 \textrm {min }}$ \\
Minimum & $23 \mathrm{~h} 00 \mathrm{~min}$ & 4.5 & $17 \mathrm{~h} \mathrm{06min}$ & $16 \mathrm{~h} \mathrm{11 \textrm {min }}$ \\
Maximum & $44 \mathrm{~h} 00 \mathrm{~min}$ & 13.2 & $47 \mathrm{~h} 44 \mathrm{~min}$ & $93 \mathrm{~h} \mathrm{16min}$
\end{tabular}

Mean analysis turnaround time (TAT) for both urine and serum are also shown with the minimum and maximum values.

used in standard antidoping analytical conditions. ${ }^{9-11}$ Before injection, urine samples were prepared as follows: $20 \mu \mathrm{L}$ of ISTDs (methyltestosterone $200 \mathrm{ng} / \mathrm{mL}$, testosterone-d3 $80 \mathrm{ng} /$ $\mathrm{mL}$, epitestosterone- $\mathrm{d} 340 \mathrm{ng} / \mathrm{mL}$, androsterone-d4 glucuronide $200 \mathrm{ng} / \mathrm{mL}$ and stanozolol-d3 $40 \mathrm{ng} / \mathrm{mL}), 1 \mathrm{~mL}$ of boiled phosphate buffer $(0.8 \mathrm{M}, \mathrm{pH} 7)$ and $50 \mu \mathrm{L}$ of $\beta$-glucuronidase from Escherichia coli were added to $2.5 \mathrm{~mL}$ of urine. Prior to incubation, samples were left for $1 \mathrm{~h}$ at $50^{\circ} \mathrm{C}$ or overnight at $37^{\circ} \mathrm{C}$ (16 h). After hydrolysis, $\mathrm{pH}$ was adjusted to 8.5-9 with carbonate buffer $\left(\mathrm{Na}_{2} \mathrm{CO}_{3} / \mathrm{NaHCO}_{3} 1 / 10\right.$, w/w) and liquid-liquid extraction (LLE) was performed with $5 \mathrm{~mL}$ of methyl tert-butyl ether. The organic layer was then transferred and evaporated to dryness, and residue was derivatised with $50 \mu \mathrm{L}$ of MSTFA$\mathrm{NH}_{4} \mathrm{I}$-ethanethiol $(1000: 2: 3, \mathrm{v} / \mathrm{w} / \mathrm{v})$ at $60^{\circ} \mathrm{C}$ for $20 \mathrm{~min}$.

Compounds of classes S3, S4, S5, S6, S7, S8 and S9 were screened using an ACQUITY UPLC liquid chromatography system coupled to a Xevo TQ-S triple quadrupole MS from Waters (Milford, Massachusetts, USA). In total $100 \mu \mathrm{L}$ of urine were diluted with $900 \mu \mathrm{L}$ of buffer (ultrapure $\mathrm{H}_{2} \mathrm{O}$ with $0.6 \mu \mathrm{g}$ / $\mathrm{mL}$ of mefruside as internal standard) before injecting into the LC-MS system running under conditions previously published, ${ }^{12}$ with a modified linear gradient going from $2 \%$ to $98 \%$ of organic phase over 6 min followed by a column re-equilibration step at initial mobile phase conditions for $3 \mathrm{~min}$. This 'dilute and shoot' approach allowed the screening of the majority of $\beta-2$ agonists, hormone and metabolic modulators, diuretics and masking agents, stimulants and cannabinoids. Glucocorticoid aliquots came from the sample preparation described above for the anabolic steroids but after the LLE step, evaporation was followed by addition of $100 \mu \mathrm{L}$ of the mixture $80 / 20 \mathrm{H}_{2} \mathrm{O}$ with $0.1 \%$ formic acid/acetonitrile to $0.1 \%$ formic acid.

The Steroidal Module of the ABP is based on the premise that samples collected on a longitudinal basis should show an athlete's physiological levels of hormones unaffected by any doping practice. ${ }^{13}$ The athlete's steroidal variables are collected and analysed over a period of time through the usual urine tests and then the steroid profile is measured. It consists of the urinary concentrations of testosterone $(\mathrm{T})$, epitestosterone $(\mathrm{E})$, androsterone $(\mathrm{A})$, etiocholanolone (Etio), $5 \alpha$-androstan- $3 \alpha, 17 \beta$-diol ( $5 \alpha$ Adiol) and $5 \beta$-androstan- $3 \alpha, 17 \beta$-diol (5 $\beta$ Adiol), together with the urine sample specific gravity (SG). T concentration is one of the six parameters included in the steroid profile. In case of abnormal steroid profiles data ( $\mathrm{T} / \mathrm{E}$ ratio over 4.0 ; $\mathrm{T}$ concentration greater than $200 \mathrm{ng} / \mathrm{mL}$ or concentration of A or Etio greater than $10000 \mathrm{ng} / \mathrm{mL}^{14}$ ), the method for determining the isotopic composition of the relevant analytes is applied. This includes gas chromatography, a subsequent combustion to $\mathrm{CO}_{2}$ and finally, mass spectrometric analyses of this gas in a specific multicollector mass spectrometer (gas chromatography combustion-isotope ratio mass spectrometry, GC-C-IRMS). The ${ }^{13} \mathrm{C} /{ }^{12} \mathrm{C}$ ratio, expressed in $\delta 13 \mathrm{C}$ values (\%), were determined for $\mathrm{T}$ metabolites and compared with that of urinary reference steroids within the sample.

Sample extraction procedures and IRMS analyses are described as 'procedure A' by Saudan et al. ${ }^{15}$

Luteinizing Hormone (LH) and human chorionic gonadotropin (hCG) were measured once in every urine sample (OOC and IC) using the Immulite 2000XPI instrument (Siemens Healthcare Diagnostics Products Ltd, Llanberis, UK) and the LH (ref. L2KLH6) and HCG kits (ref. L2KCG6). In case of hCG confirmation procedure, the intact hCG was detected by sandwich ELISA method (Human Chorionic Gonadotropin ELISA, ALPCO, USA).

While every urine sample was analysed, serum samples were partly screened for erythropoiesis-stimulating agents (ESAs), hematide and recombinant human growth hormone (rhGH). Among the 773 serums collected during the OOC period, 65 were screened for hematide, 203 for ESAs and 198 for rhGH whereas hematide, ESAs and rhGH were screened IC in 17, 135 and 125 samples, respectively. On reaching the laboratory, serum samples were centrifuged and aliquoted to follow WADA guidelines, especially regarding rhGH analyses.

Previously published hematide method $^{16}$ was applied using $100 \mu \mathrm{L}$ of serum submitted to an enzymatic digestion with subtilisin and a solid phase extraction step before running on the ultra-high performance liquid chromatography-tandem massspectrometry (UHPLC-MS-MS) analytical tool as described above from Waters.

ESAs were tested in serum samples subjected to affinity purification with EPO Purification Kit (MAIIA Diagnostics). Samples were passed to $10 \%$ in buffer $(20 \mathrm{mM}$ Tris $\mathrm{pH} 7.5,0.1 \mathrm{M}$ $\mathrm{NaCl}, 0.1 \%$ Tween 20 and $0.02 \% \mathrm{NaN}_{3}$ ). The diluted serums were passed through Millex GV filters $(0.22 \mu \mathrm{m})$, purified by immunoaffinity and eluated with $50 \mu \mathrm{L}$ Desorption (low $\mathrm{pH}$ ) buffer. Then, $\mathrm{pH}$-neutralisation was performed by addition of $5 \mu \mathrm{L}$ adjustment buffer (0.1 M Bis-Tris pH 7.0, 0.1 M NaCl, $10 \mathrm{mM}$ glycine, $0.1 \%$ Tween 20 and $0.02 \% \quad \mathrm{NaN}_{3}$ ). SARCOSYL-PAGE was performed as previously described by Reichel et $a l^{17}$ with minor modifications. BlotCycler technology (Precision Biosystems, Mansfield, Ohio, USA) was used for incubations (blocking and antibodies) and washing steps at $4^{\circ} \mathrm{C}$.

rhGH isoforms analyses were made using the WADAapproved kits ${ }^{18}$ and by following manufacturer instructions. Briefly, $150 \mu \mathrm{L}$ of serum were loaded with $50 \mu \mathrm{L}$ of furnished buffer. After incubation ( $2 \mathrm{~h}$ at room temperature), tubes were extensively washed. A total of $200 \mu \mathrm{L}$ of acridinium-labelled secondary antibodies were added and incubated for $2 \mathrm{~h}$. After systematic washing, tubes were revealed with hydrogen peroxide. A luminometer (LB953, Berthold, Switzerland) allowed the quantification of the signal emitted by acridinium oxidation. Calculation of rhGH isoforms ratio was based on the standard curves loaded in parallel from routine samples.

The 1077 EDTA samples (771 OOC and 306 IC) were analysed after being received at the laboratory and according to the ABP Operating Guidelines. ${ }^{19}$ Every sample was analysed twice, on the same day, on the same haematology analyser (Sysmex XN-2000; Sysmex Europe, Norderstedt, Germany). If the results between two measures on the same instrument were $>0.1 \mathrm{~g} / \mathrm{dL}$ for haemoglobin (HGB) and/or $>0.15 \%$ for reticulocytes percentage (RET\%) (for values equal or below $1.00 \%$ ) or $0.25 \%$ (for values above $1.00 \%$ ), duplicate measurements were repeated once again on the same analyser. Instruments were submitted to regular internal and external quality control procedures as required by the Standards of Laboratory Medicine. 

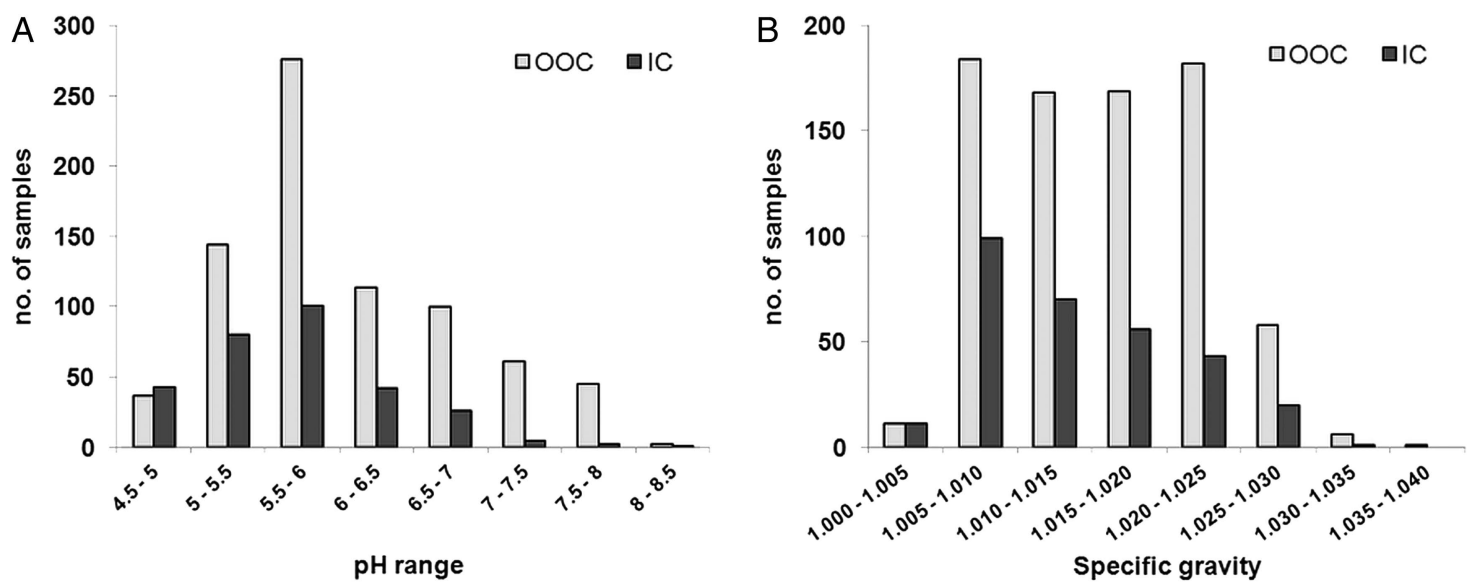

Figure 4 pH (A) and specific gravity (B) of OOC and IC urine samples from the 2014 FIFA World Cup (IC, in competition; OOC, out of competition).

All FIFA biological samples were analyzed in dedicated batches which included regular positive and negative controls as described in the standard operating procedures which are a part of the ISO 17025 scope of accreditation of the Swiss Laboratory for Doping Analyses and as per procedures of the International Standard for Laboratories. ${ }^{3}$

\section{RESULTS}

\section{Preanalyses}

Prior to initial testing procedures in the laboratory, two preanalytical measurements were performed on a sample: $\mathrm{pH}$ and SG. As shown in figure $4 \mathrm{~A}, \mathrm{pH}$ is distributed normally for all urine samples, with no value exceeding the critical value of 8.5. No significant difference was found between OOC and IC samples with regard to $\mathrm{pH}$ and the distribution is comparable to previous results described in similar football competitions. ${ }^{20} 21$

SG was also measured on all urine samples for preanalytical purposes and for the correction of the concentrations of endogenous steroid metabolites according to the WADA technical document dedicated to endogenous anabolic androgenic steroids measurement. ${ }^{14}$ This parameter also indicates the hydration state of the player at the time of sample collection.

The distribution of the SG values for all IC and OOC urine sample tests is shown in figure 4B. Higher SGs were measured for the OOC urine samples (mean: 1.017) compared to the IC samples (mean: 1.014).

\section{OVERALL RESULTS OF ANTIDOPING ANALYSES Clenbuterol}

Among the 779 urine samples collected OOC, 4 samples, collected in Mexico and Spain, showed traces of clenbuterol. Two of these samples were reported as negative because clenbuterol concentrations were below the reporting limit of the laboratory $(5 \mathrm{pg} / \mathrm{mL})$ whereas the other two samples contained clenbuterol concentration of about $50 \mathrm{pg} / \mathrm{mL}$ and were reported as adverse analytical findings (AAF).

\section{Tramadol and formestane}

Among the samples collected OOC, 7 contained tramadol parent compound (ranging from 16 to $5 \mu \mathrm{g} / \mathrm{mL}$ ) and metabolite (ranging from $130 \mathrm{ng} / \mathrm{mL}$ to $3.5 \mu \mathrm{g} / \mathrm{mL}$ ). One urine sample contained an abnormally high concentration of formestane $(73 \mathrm{ng} / \mathrm{mL})$.

\section{Glucocorticoids, hCG and LH}

Among the 300 IC samples, 3 contained glucocorticoids (prednisone and prednisolone, triamcinolone acetonide, budesonide metabolite) above the WADA minimum required performance limit (MRPL) of $30 \mathrm{ng} / \mathrm{mL}$ and in another sample prednisolone was detected at a concentration below the MRPL. ${ }^{22}$ Immulite screening quantification of hCG revealed that one sample contained hCG at a concentration of $13.6 \mathrm{mIU} / \mathrm{mL}$. Additionally, one sample presented an elevated $\mathrm{LH}$ concentration $(69 \mathrm{mIU} / \mathrm{mL})$.
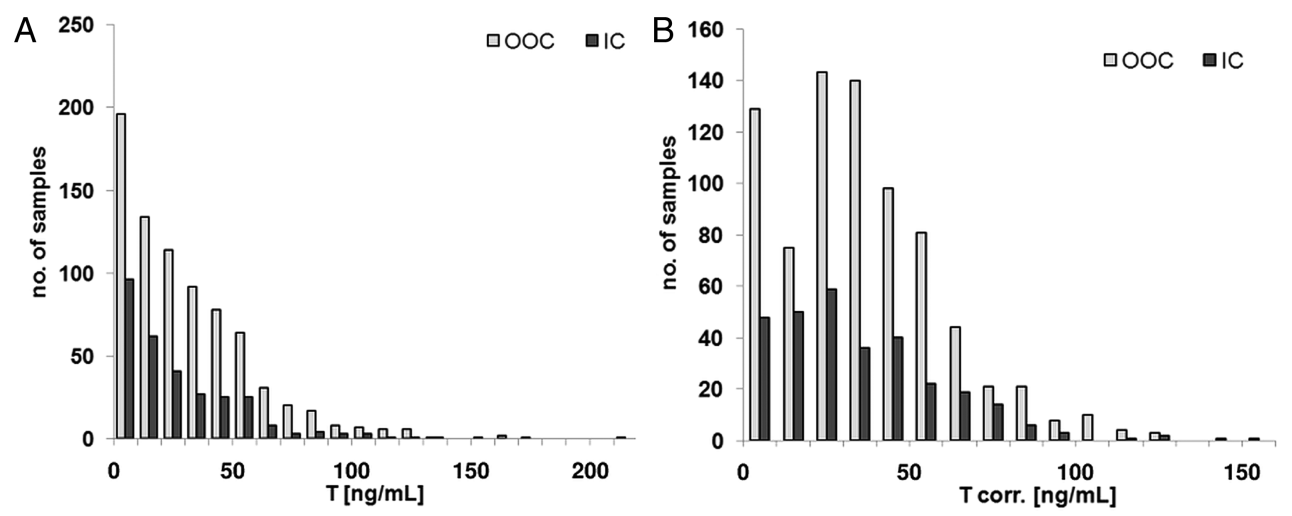

Figure 5 Distribution of T concentrations (in $\mathrm{ng} / \mathrm{mL}$ ) in urine samples from the 2014 FIFA World Cup. (A) T concentrations without correction. (B) T concentrations after correction with SG (IC, in competition; OOC, out of competition, SG, specific gravity; T, testosterone). 


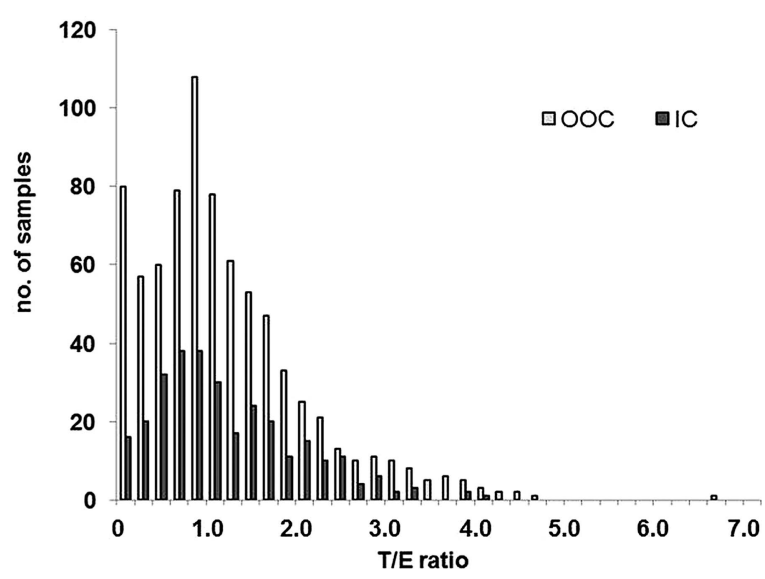

Figure 6 T/E ratio distributions measured in urine collected out-ofcompetition (OOC) and in competiton (IC).
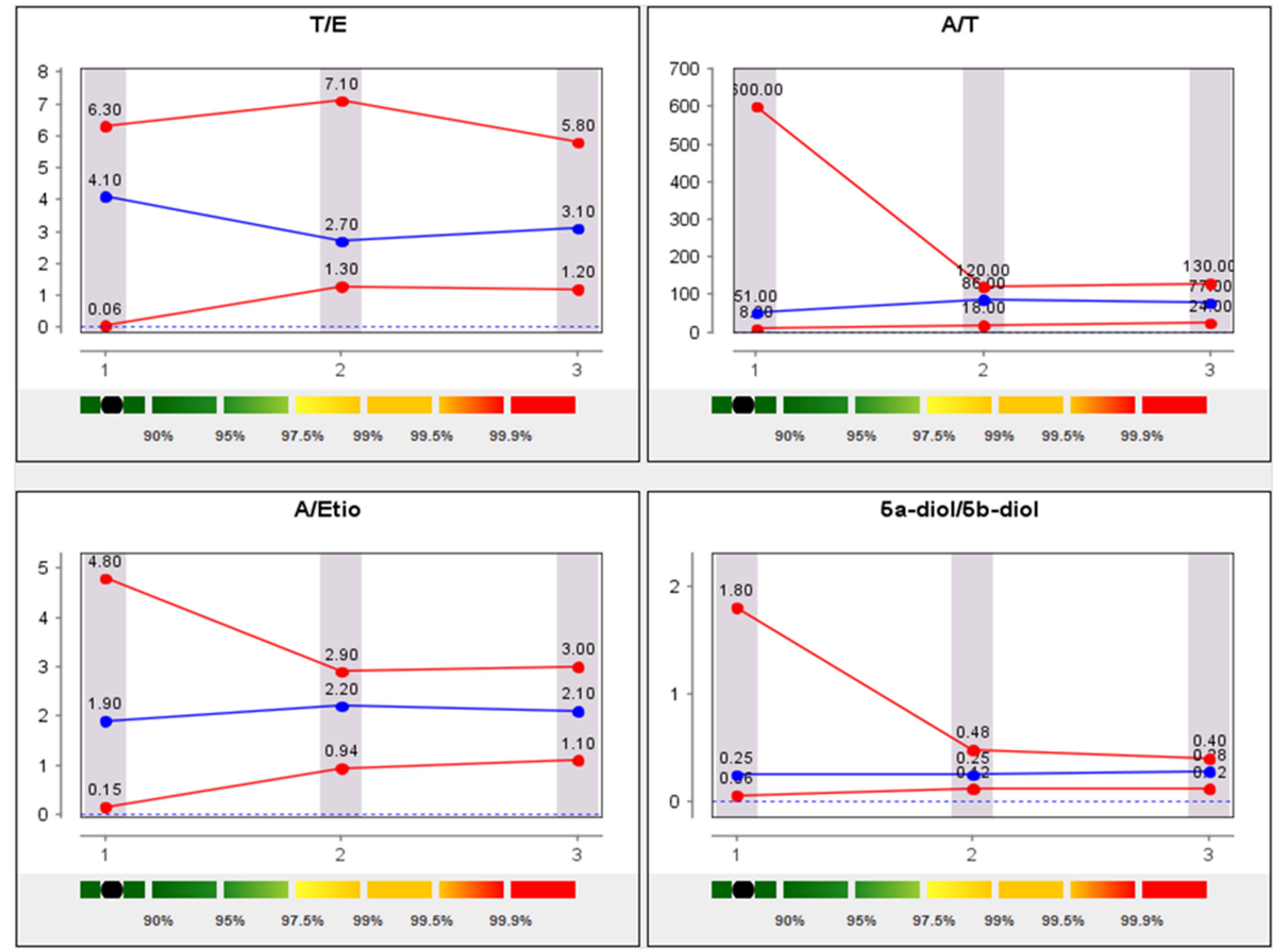

\begin{tabular}{|c|c|c|c|c|c|c|c|c|c|c|c|c|c|c|}
\hline Test Type & Day & $\begin{array}{c}\mathrm{T} \\
{[\mathrm{ng} / \mathrm{mL}]}\end{array}$ & $\begin{array}{c}E \\
{[\mathrm{ng} / \mathrm{mL}]}\end{array}$ & T/E & A/T & $\begin{array}{c}\mathrm{A} \\
{[\mathrm{ng} / \mathrm{mL}]}\end{array}$ & \begin{tabular}{|c|} 
Etio \\
[ng/mL]
\end{tabular} & A/Etio & \begin{tabular}{|l|}
$5 \alpha$ Adiol \\
[ng/mL]
\end{tabular} & $\begin{array}{l}\text { 5BAdiol } \\
{[\mathrm{ng} / \mathrm{mL}]}\end{array}$ & $5 \alpha / 5 \beta$ & $\mathrm{pH}$ & SG & $\begin{array}{c}\mathrm{LH} \\
{[\mathrm{mlU} / \mathrm{ml}]}\end{array}$ \\
\hline$O O C$ & 0 & 138 & 29.5 & 4.1 & 51.1 & 7018 & 3744 & 1.9 & 100 & 393 & 0.3 & 5 & 1.022 & 22.6 \\
\hline IC & 5 & 124 & 41.3 & 2.7 & 86.2 & 10708 & 4845 & 2.2 & 105 & 425 & 0.2 & 5.5 & 1.028 & 22.1 \\
\hline \multirow[t]{4}{*}{ IC } & 14 & 93.4 & 25.3 & 3.1 & 77.2 & 7214 & 3461 & 2.1 & 88.8 & 318 & 0.3 & 5 & 1.027 & 22.0 \\
\hline & Mean & 118 & 32.0 & 3.30 & 71.5 & 8313 & 4017 & 2.1 & 98 & 379 & 0.3 & 5 & 1.026 & 22.2 \\
\hline & $S D$ & 23 & 8.3 & 0.72 & 18.2 & 2076 & 731 & 0.2 & 8.4 & 55.0 & 0.1 & 0.3 & 0.003 & 0.3 \\
\hline & $\mathrm{CV}$ & 19.1 & 25.9 & 21.9 & 25.5 & 25.0 & 18.2 & 7.4 & 8.6 & 14.5 & 21.7 & 5.6 & 0.3 & 1.4 \\
\hline
\end{tabular}

Figure 7 Steroid passport and concentrations (without SG correction) of a player with a normal UGT2B17 genotype (A, androsterone; CV, coefficient of variation; $E$, epitestosterone; Etio, etiocholanolone; IC, in competition; LH, luteinizing hormone; $00 C$, out-of-competition; SG, specific gravity; T, testosterone; $5 \alpha$ Adiol, $5 \alpha$-androstan-3a,17 $\beta$-diol; $5 \beta$ Adiol, $5 \beta$-androstan-3a,17 $\beta$-diol).

\section{Amphetamine}

One IC sample was reported as AAF for the presence of amphetamine at a concentration of about $600 \mathrm{ng} / \mathrm{mL}$. However, the presence of the substance was explained by a valid therapeutic use exemption (TUE) for a treatment against attention deficit hyperactivity disorder.

\section{Endogenous steroid profiles}

Distribution of $\mathrm{T}$ concentrations with and without correction with SG is depicted in figure 5. Without correction, a high number of samples have a T concentration in the low range of ng/mL (figure 5A). Considering the SG distribution, a shown in figure 4B, more samples have an SG lower than 1.020 , which then produced an increase of apparent $\mathrm{T}$ concentration after correction (figure 5B). Adjustment of $\mathrm{T}$ concentrations was calculated using the formula described in the technical document: ${ }^{14}$ 

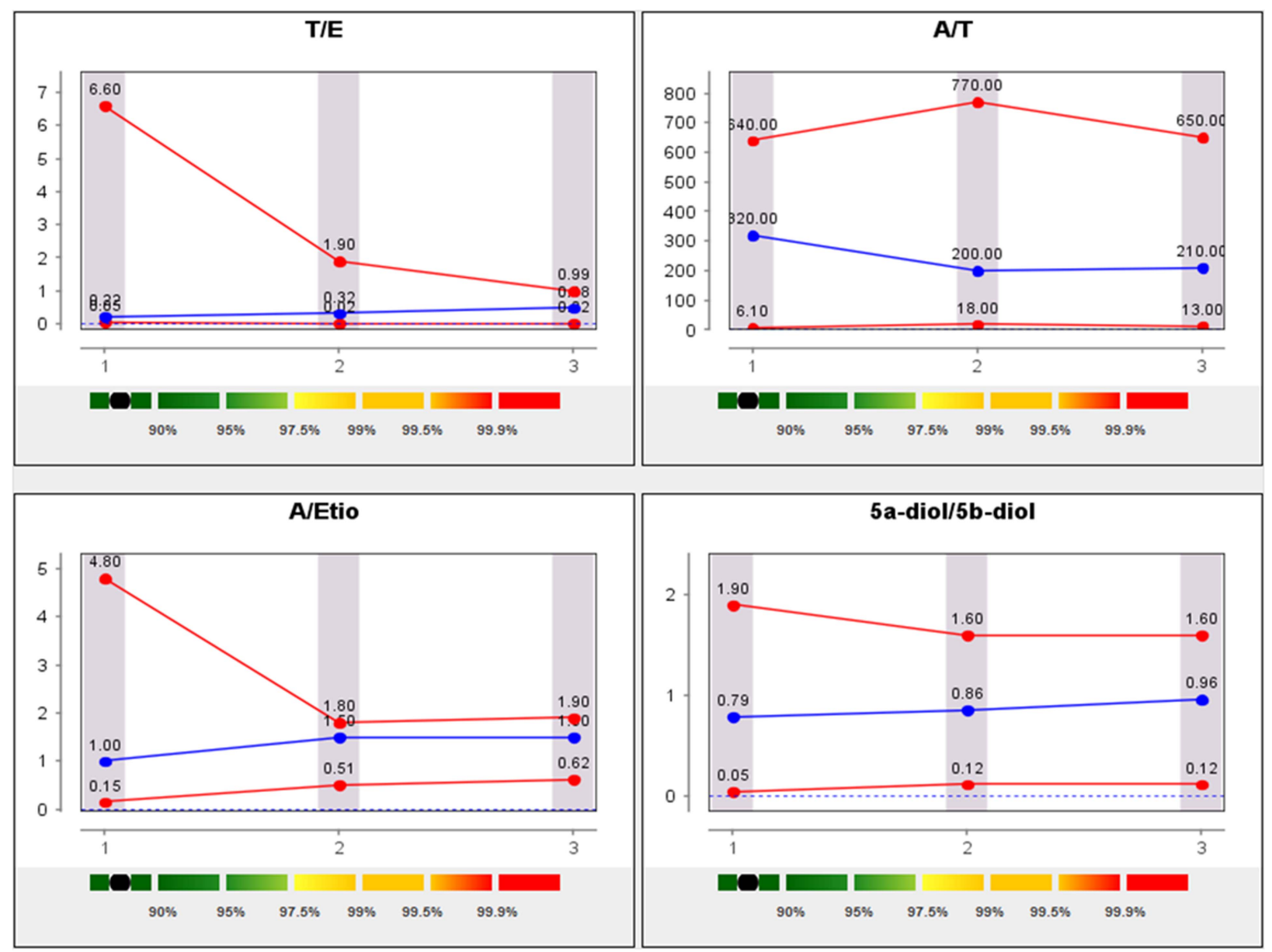

\begin{tabular}{|c|c|c|c|c|c|c|c|c|c|c|c|c|c|c|}
\hline Test Type & Day & $\begin{array}{c} \\
{[\mathrm{ng} / \mathrm{mL}]}\end{array}$ & \begin{tabular}{|c|}
$E$ \\
{$[n g / m L]$}
\end{tabular} & $T / E$ & A/T & $\begin{array}{c}A \\
{[\mathrm{ng} / \mathrm{mL}]}\end{array}$ & $\begin{array}{c}\text { Etio } \\
{[\mathrm{ng} / \mathrm{mL}]}\end{array}$ & A/Etio & \begin{tabular}{|l|}
$5 \alpha$ Adiol \\
[ng/mL]
\end{tabular} & $\begin{array}{l}\text { 5BAdiol } \\
\text { [ng/mL] }\end{array}$ & $5 \alpha / 5 \beta$ & $\mathrm{pH}$ & SG & $\begin{array}{c}\mathrm{LH} \\
{[\mathrm{mlU} / \mathrm{ml}]}\end{array}$ \\
\hline$O O C$ & 0 & 4.8 & 23 & 0.22 & 321 & 1557 & 1498 & 1.0 & 45 & 57 & 0.8 & 6 & 1.012 & 10.7 \\
\hline IC & 100 & 2.1 & 6 & 0.32 & 208 & 429 & 291 & 1.5 & 11 & 13 & 0.9 & 6.5 & 1.006 & 2.8 \\
\hline \multirow[t]{4}{*}{ IC } & 120 & 1.7 & 3.3 & 0.48 & 211 & 357 & 232 & 1.5 & 11.7 & 12.2 & 1.0 & 6.5 & 1.005 & 2.0 \\
\hline & Mean & 2.9 & 11 & 0.34 & 247 & 781 & 674 & 1.3 & 23 & 27.6 & 0.90 & 6.3 & 1.008 & 5.17 \\
\hline & $S D$ & 1.7 & 10.6 & 0.13 & 64 & 673 & 715 & 0.3 & 19.6 & 25.8 & 0.10 & 0.3 & 0.004 & 4.81 \\
\hline & $\mathrm{CV}(\%)$ & 59 & 100 & 39 & 26 & 86 & 106 & 22 & 86 & 93 & 11.1 & 4.6 & 0.4 & 93 \\
\hline
\end{tabular}

Figure 8 Steroid passport and concentrations (without SG correction) of a player with del/del UGT2B17 genotype (A, androsterone; CV, coefficient of variation ;E, epitestosterone; Etio, etiocholanolone; IC, in competition; LH, luteinizing hormone; OOC, out-of-competition; SG, specific gravity; T, testosterone; $5 \alpha$ Adiol, $5 \alpha$-androstan-3 $\alpha, 17 \beta$-diol; $5 \beta$ Adiol, $5 \beta$-androstan-3 $\alpha, 17 \beta$-diol).

$$
\text { Conc }_{\text {corrected }}=\text { Conc }_{\text {measured }} \times(1.020-1) /(S G-1)
$$

The distribution observed after correction is similar to the $\mathrm{T} / \mathrm{E}$ ratio distribution illustrated in figure 6 .

Nine OOC samples having a $\mathrm{T} / \mathrm{E}$ ratio higher than 4.0 (ranging from 4.2 to 6.7 ) and one IC sample having a T/E ratio of 4.1 were analysed by GC-C-IRMS to determine a potential exogenous origin of $\mathrm{T}$ abuse. All of these were reported as negative as IRMS results clearly showed an endogenous origin of $\mathrm{T}$ and/or its precursors. Steroid profile data of players tested 3 times or more (OOC and IC) were integrated in the adaptive model of the Steroidal module of the ABP. Two examples are given in figures 7 and 8 .

\section{Haematological parameters}

Whole blood samples were collected from all the qualified players during the OOC tests and all tested players after the games. The WADA procedures for the blood tests, as described in the operational guidelines for the biological passport, were entirely applied, except for the $2 \mathrm{~h}$ delay before blood collection after the match. In the operating guidelines, the appendix $\mathrm{A}$ is dedicated to the blood sample collection requirements. ${ }^{19}$ "If collection occurs after training or Competition, test planning shall ... ensure testing does not occur within two hours of such activity...If for some reason, the Sample was taken within two hours of training or competition, the nature, duration and intensity of the exertion shall be recorded."

For logistical reasons, the $2 \mathrm{~h}$ wait after exercise was not feasible at the FIFA World Cup and, therefore, was not applied. In fact, antidoping tests in football right after the game have always been challenging because of the players. In principle, blood collection is not time-consuming, in contrast to urine sampling. For this reason, the antidoping authorities of FIFA collect the blood tests as soon as the player arrives in the 
Table 2 Blood passport values of players depending on their position and the time spent on the field

\begin{tabular}{|c|c|c|c|c|c|c|c|c|}
\hline \multirow{2}{*}{$\begin{array}{l}\text { Position and time spent on } \\
\text { the field (minimum) }\end{array}$} & \multicolumn{4}{|c|}{ In competition } & \multicolumn{4}{|c|}{ Precompetition } \\
\hline & $\mathrm{n}$ & HGB (g/dL) & RET (\%) & Off-score & $\mathrm{n}$ & HGB (g/dL) & RET (\%) & Off-score \\
\hline Defender & 96 & 14.9 & 1.24 & 82.9 & 194 & 14.9 & 1.21 & 83.9 \\
\hline $0-45$ & 45 & 14.8 & 1.25 & 81.1 & & & & \\
\hline $45-90$ & 3 & 14.8 & 0.96 & 89.7 & & & & \\
\hline 90-135 & 48 & 15.1 & 1.25 & 84.2 & & & & \\
\hline Forward & 78 & 15.1 & 1.26 & 84.0 & 140 & 15.1 & 1.22 & 85.4 \\
\hline $0-45$ & 38 & 14.8 & 1.27 & 80.8 & & & & \\
\hline $45-90$ & 19 & 15.6 & 1.31 & 88.4 & & & & \\
\hline 90-135 & 21 & 15.1 & 1.20 & 85.9 & & & & \\
\hline Goalkeeper & 43 & 15.0 & 1.15 & 86.2 & 80 & 15.2 & 1.24 & 86.5 \\
\hline $0-45$ & 26 & 15.0 & 1.11 & 87.4 & & & & \\
\hline $45-90$ & 2 & 16.1 & 1.49 & 87.4 & & & & \\
\hline $90-135$ & 15 & 14.9 & 1.18 & 84.0 & & & & \\
\hline Midfielder & 88 & 15.3 & 1.25 & 86.2 & 199 & 15.1 & 1.21 & 85.8 \\
\hline $0-45$ & 42 & 15.2 & 1.26 & 85.6 & & & & \\
\hline $45-90$ & 15 & 15.5 & 1.11 & 92.6 & & & & \\
\hline 90-135 & 31 & 15.2 & 1.30 & 83.9 & & & & \\
\hline Unknown & & & & & 156 & 15.1 & 1.20 & 85.5 \\
\hline Total/mean & 305 & 15.1 & 1.24 & 84.6 & 769 & 15.1 & 1.21 & 85.3 \\
\hline
\end{tabular}

antidoping collection room, directly after the game. Depending on the location of the antidoping room in the stadium and the duration of press interviews, the time after exercise can vary from 15 and $90 \mathrm{~min}$, if the player was still on the pitch at the end of the game. Furthermore, the nature and the duration of participation in the competition were recorded.

Even though the World Cup tournament is not considered as a controlled study, the data obtained on the field can give a good indication of the real effect of a football match on these parameters. Figure 9 shows that the parameters measured for the red cell lines are not significantly different between IC and OOC samples.

The cumulative frequency distribution curves of the haemoglobin concentrations and the reticulocyte percentage, the two main components of the blood passport (figure 10) do not show any difference between OOC and IC samples. Contrary to what was shown at Euro 2008, ${ }^{21}$ there was no significant effect of the competition on the values of these critical blood parameters.

Most of the players did not have more than 2-3 blood tests (1 OOC and 1-2 IC) then it was not deemed relevant to establish a blood passport at this stage for all players. Groups of players were established as a function of their position in the field and the time they played during the matches.

As observed in table 2, there is homogeneity in the blood data between the different groups, with no significant effect within the groups, if the collection was done IC or OOC.

\section{DISCUSSION}

\section{Preanalyses}

The measurement of $\mathrm{pH}$ allowed the laboratory to check if the urine degraded before or during the transportation process, for example, by bacterial contamination. In the case of an elevated $\mathrm{pH}(>8.5)$, the steroid profile could be affected as bacterial contamination was clearly described to be a confounding factor impacting the endogenous anabolic steroid concentrations ( $\mathrm{T}$ and related compounds) and the profile interpretation. ${ }^{23} 24$ SG was a useful parameter to evaluate the hydration status during the competition phase, especially in hot and extreme weather conditions. During the competition phase, the SG results show that all players were well hydrated, which was not necessarily the case during the OOC tests.

\section{Clenbuterol}

Clenbuterol abuse in sports is an important topic in the fight against doping as this compound is used and authorised for animal feeding in specific countries. Meat contamination has previously resulted in the presence of a small amount of clenbuterol in urine samples of tested football players as well as volunteers. $^{12}$ 25-28 Clenbuterol abuse in different countries is far from solved and AAF in urine samples collected in different countries, particularly in Mexico, continues to be present on a regular basis.

\section{Tramadol and formestane}

Tramadol is part of the WADA monitoring programme and laboratories report these cases as negative. Formestane is

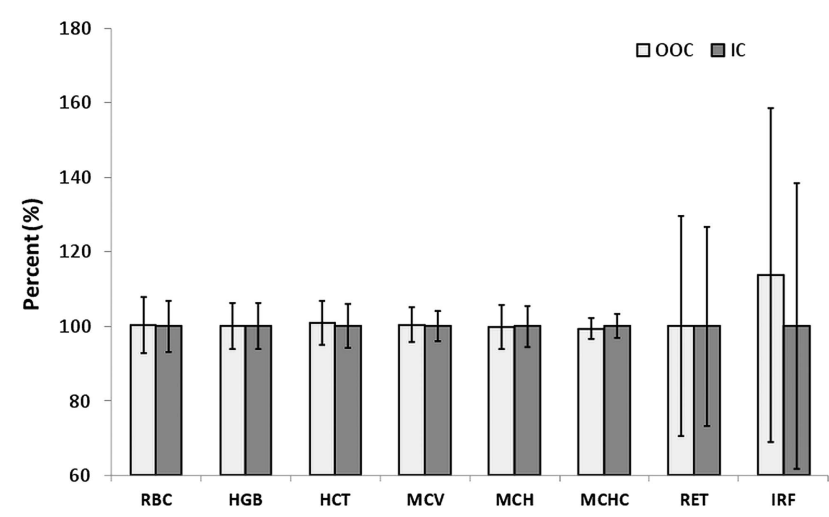

Figure 9 Blood parameters in $\mathrm{OOC}$ and IC samples. Percentage of $\mathrm{OOC}$ values were calculated considering the IC data as $100 \%(\mathrm{HCT}$, haematocrit; HGB, haemoglobin; IC, in competition; IRF, immature reticulocyte fraction; $\mathrm{MCH}$, mean corpuscular haemoglobin; $\mathrm{MCHC}, \mathrm{MCH}$ concentration; MCV, MC volume; OOC, out-of-competition; RBC, red blood cell (erythrocyte) count and Ret, reticulocyte percentage. 

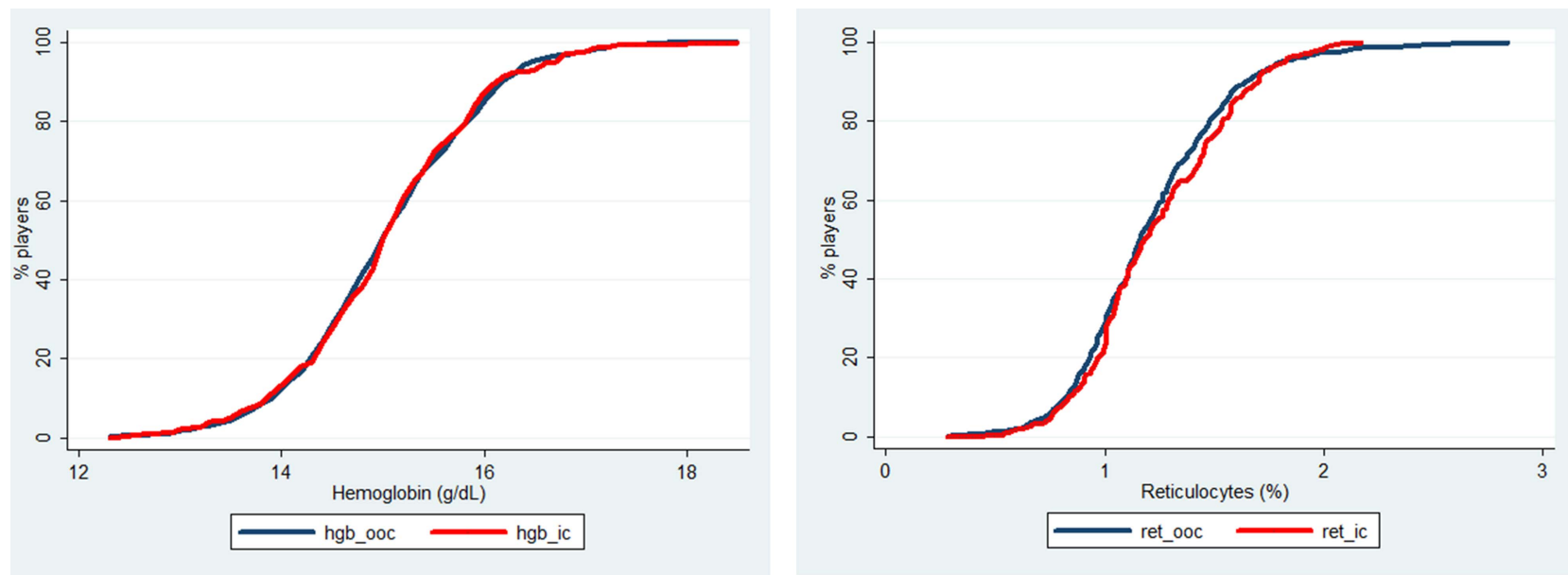

Figure 10 Cumulative frequency distribution curves for haemoglobin (left panel) and reticulocytes (right panel) in the in competition (red line) and out-of-competition (black line) samples.

considered as a potent aromatase inhibitor that could minimise side effects of anabolic steroids abuse by reducing the conversion into oestrogens ${ }^{29}{ }^{30}$ and therefore, it is included in the S4 class of the WADA forbidden list. Formestane could also stem from endogenous origin. ${ }^{31}$ The WADA defines a threshold for which additional analysis is performed to prove the endogenous or exogenous origin of this substance. During the 2014 FIFA World Cup in Brazil, the technical document stated that "GC-C-IRMS analysis shall be conducted before reporting an Adverse Analytical Finding for Samples containing formestane at less than $150 \mathrm{ng} / \mathrm{mL}$ ". ${ }^{22}$ GC-C-IRMS confirmation analysis was performed following the method published by Piper et al ${ }^{30}$ and the results indicated an endogenous origin of formestane leading to a negative reporting of the sample.

\section{Glucocorticoids, hCG and LH}

Glucocorticoids are part of class S9 of the WADA list ${ }^{32}$ and are prohibited when administered by oral, intravenous, intramuscular or rectal routes. Administration through alternative routes is justified by a TUE ruled by the dedicated WADA International Standard for TUEs (ISTUE). ${ }^{33}$ Three urine samples contained glucocorticoids above the MRPL; after consultation with the FIFA Medical Board, a valid TUE was effective for all of them and the results were reported as negative.

According to the WADA guidelines for reporting and management of hCG findings, ${ }^{34}$ "samples producing a concentration of total hCG above $5 \mathrm{mIU} / \mathrm{mL}$ on the Initial Testing Procedure, laboratory shall perform a confirmation procedure to quantify intact hCG." If the intact form concentration is still above $5 \mathrm{mIU} / \mathrm{mL}$, the laboratory reports an AAF, otherwise an atypical finding (ATF) report is produced. The confirmation analysis was performed on the sample containing performed $13.6 \mathrm{mIU} / \mathrm{mL}$. ELISA kit showed that intact hCG fell below $5 \mathrm{mIU} / \mathrm{mL}$ and thus, the laboratory reported the sample as ATF. No threshold has been defined for $\mathrm{LH}$ in urine to report a case as AAF, but high amount of urinary $\mathrm{LH}$ could be a marker of $\mathrm{T}$ or other anabolic steroids manipulation. ${ }^{35} 36$ A close analysis of the steroid profile of this sample allowed the laboratory to consider the case as negative.

\section{Endogenous steroid profiles}

The OOC distribution of the $\mathrm{T} / \mathrm{E}$ ratio clearly shows the already published bimodal figure ${ }^{9} 3738$ which was explained by genetic polymorphism of the enzyme involved in the
T metabolism. ${ }^{39-41}$ A complete deletion of the UGT2B17 gene (del/del genotype) involved in the phase II (glucuronidation) metabolism results in a decrease of urinary T excretion and thus, results in lower $\mathrm{T} / \mathrm{E}$ ratio compared to the normal mean value of 1-1.2. In contrast, the IC samples repartition of the $T / E$ ratios does not follow this bimodal distribution. This could stem from the early disqualification of the Asian teams after the first round of the tournament, as the del/del genotype has been shown to be significantly higher among Asian people compared to the other ethnicities. ${ }^{42} 43$

The ABP uses the athlete's own values rather than population values as a basis for evaluation. The longitudinal profile of specific markers ( $5 \alpha$ Adiol/5 $\beta$ Adiol, $\mathrm{A} / \mathrm{T}$ and $\mathrm{T} / \mathrm{E}$ ratios) was analysed to determine if any atypical patterns were present. Before the introduction of the ABP steroid module, if the T/E ratio was greater than 4, the laboratory had to perform an IRMS analysis to detect the use of exogenous (from outside the body) steroids. With this 'population reference' approach, only high values resulted in IRMS testing. Now, with the adaptive model, the intraindividual variation of specific markers is considered to perform or not to perform an IRMS test.

An important feature of the urinary steroid profile is the stability of the ratios issued from steroid quantification. Whereas $\mathrm{A} /$ Etio, $5 \alpha$ Adiol/5 5 Adiol and $\mathrm{A} / \mathrm{T}$ are more subjected to variations, ${ }^{9}$ the $\mathrm{T} / \mathrm{E}$ ratio has proven to be stable over time. ${ }^{44-47}$ This characteristic has been at the origin of the implementation of the steroidal module of the ABP. ${ }^{8} 3848$ Since January 2014, the adaptive model is applied on all the analytical data provided by the WADA accredited laboratories in Antidoping Administration and Management System (ADAMS). Figures 7 and 8 depict the longitudinal profiles of a 'normal' subject and most probably $\mathrm{del} / \mathrm{del}$ player, respectively. Even if no genotyping has been performed on the players, it is highly credible that participants with a collapsed $\mathrm{T}$ concentration in urine and thus with low $\mathrm{T} /$ $\mathrm{E}$ ratio (below 0.5 ) are depleted in enzyme responsible for $\mathrm{T}$ excretion in urine. As observed in figures 7 and 8 , the adaptive model shows stable measurement during the OOC and IC period. The fact that all samples were analysed in the same laboratory with the same analytical procedure favoured the stability of the ABP profiles. Even if the robustness and reliability of steroid profile quantification is insured by WADA from among all the accredited laboratories, it is a well-known fact that variability increases when several methods and techniques are used. ${ }^{23} 49$ 


\section{Summary}

The main lesson learned from the FIFA World Cup 2014 were: (1) meticulous organisation of antidoping tests on the field and well-controlled shipments of samples to the laboratory by the antidoping authority does not compromise the samples. This allows the accredited laboratory to provide valid results. (2) No differences were observed between ou-of-competition and postcompetition for haematological values.

Acknowledgements The authors would like to thank all the technical and administrative staff of the Swiss Laboratory for Doping Analyses who were fully engaged during the OOC and IC periods linked to 2014 FIFA World Cup Brazil. They are grateful to Violette Allora, Anne Ballif, Charlotte Brunner, Christèle Carruzzo, Mélanie Johner, Alexandra Melchior, Roxane Rochat, Rita Saugy, Magali Wicht, Giuseppe Ciminera and Michel Delcioni for their precious and reliable collaboration. The authors also thank the FIFA collaborators, namely, Martin Vaso, Monika Keller, Anja König, Philipp Tobler and Alexis Weber for their logistical and technical support before and during the 2014 FIFA World Cup Brazil 2014.

Contributors JD and MS conceived the study design and the antidoping programme. NB, NJ, CE, BM, CS, SG, NL, FM, RN, LP and NR managed the samples and data analyses. NB and MS wrote the first draft and all authors contributed to the revision of the final manuscript.

\section{Competing interests None.}

Provenance and peer review Not commissioned; externally peer reviewed.

Open Access This is an Open Access article distributed in accordance with the Creative Commons Attribution Non Commercial (CC BY-NC 4.0) license, which permits others to distribute, remix, adapt, build upon this work non-commercially, and license their derivative works on different terms, provided the original work is properly cited and the use is non-commercial. See: http://creativecommons.org/ licenses/by-nc/4.0/

\section{REFERENCES}

1 Dvorak J, Graf-Baumann T, D'Hooghe M, et al. FIFA's approach to doping in football. Br J Sports Med 2006;40(Suppl 1):i3-12.

2 World Anti-Doping Agency. The World Anti-Doping Code: International Standard for Testing. 2012. http://www.wada-ama.org/Documents/World_Anti-Doping_Program/ WADP-IS-Testing/2012/WADA IST 2012 EN.pdf (accessed 27 Feb 2014).

3 World Anti-Doping Agency. The World Anti-Doping Code: International Standard for Laboratories. 2012. https://wada-main-prod.s3.amazonaws.com/resources/files/ WADA_Int_Standard_Laboratories_2012_EN.pdf (accessed 29 Jan 2015).

4 Dvorak J, Saugy M, Pitsiladis YP. Challenges and threats to implementing the fight against doping in sport. Br J Sports Med 2014;48:807-9.

5 Dvorak J, Baume N, Botre F, et al. Time for change: a roadmap to guide the implementation of the World Anti-Doping Code 2015. Br J Sports Med 2014;48:801-6.

6 Dvorak J, Budgett R, Saugy M, et al. Drawing the map to implement the 2015 World Anti-Doping Code. Br J Sports Med 2014;48:800.

7 Saugy M, Lundby C, Robinson N. Monitoring of biological markers indicative of doping: the athlete biological passport. Br J Sports Med 2014;48: 827-32.

8 Vernec AR. The Athlete Biological Passport: an integral element of innovative strategies in antidoping. Br J Sports Med 2014;48:817-19.

9 Ayotte C, Goudreault D, Charlebois A. Testing for natural and synthetic anabolic agents in human urine. J Chromatogr B Biomed App/ 1996;687:3-25.

10 Marcos J, Pascual JA, de la Torre $X$, et al. Fast screening of anabolic steroids and other banned doping substances in human urine by gas chromatography/tandem mass spectrometry. J Mass Spectrom 2002;37:1059-73.

11 Van Eenoo P, Van Gansbeke W, De Brabanter N, et al. A fast, comprehensive screening method for doping agents in urine by gas chromatography-triple quadrupole mass spectrometry. J Chromatogr A 2011;1218:3306-16.

12 Nicoli R, Petrou M, Badoud F, et al. Quantification of clenbuterol at trace level in human urine by ultra-high pressure liquid chromatography-tandem mass spectrometry. J Chromatogr A 2013;1292:142-50.

13 Geyer $H$, Schanzer W, Thevis M. Anabolic agents: recent strategies for their detection and protection from inadvertent doping. Br J Sports Med 2014;48:820-6.

14 World Anti-Doping Agency. Endogenous anabolic androgenic steroids: measurement and reporting, version 2.0. 2014. https://wada-main-prod.s3.amazonaws.com/ resources/files/wada-td2014eaas-v2-endogenous-anabolic-androgenic-steroidsmeasurement-and-reporting-en_0.pdf (accessed 6 Feb 2015).

15 Saudan C, Emery C, Marclay F, et al. Validation and performance comparison of two carbon isotope ratio methods to control the misuse of androgens in humans. J Chromatogr B Analyt Technol Biomed Life Sci 2009;877:2321-9.
16 Moller I, Thomas A, Geyer H, et al. Synthesis, characterisation, and mass spectrometric detection of a pegylated EPO-mimetic peptide for sports drug testing purposes. Rapid Commun Mass Spectrom 2011;25:2115-23.

17 Reichel C, Abzieher F, Geisendorfer T. SARCOSYL-PAGE: a new method for the detection of MIRCERA- and EPO-doping in blood. Drug Test Anal 2009;1:494-504.

18 World Anti-Doping Agency. World Anti-Doping Progam, Guidelines, hGH isoform differential immunoassays. 2014. https://wada-main-prod.s3.amazonaws.com/ resources/files/WADA-Guidelines-for-hGH-Differential-Immunoassays-v2.1-2014-EN. pdf (accessed 29 Jan 2015).

19 World Anti-Doping Agency. Athlete Biological Passport Operating Guidelines \& Compilation of Required Elements. 2013. http://www.wada-ama.org/Documents/ Science_Medicine/Athlete_Biological_Passport/WADA-ABP-Operating-Guidelines_v4. 0-EN.pdf (accessed 27 Feb 2014).

20 Earl M, Vouillamoz M, Kwiatkowska D, et al. The uefa euro 2012 anti-doping programme - scientific review. Biol Sport 2014;31:85-93.

21 Vouillamoz M, Thom C, Grisdale R, et al. Anti-doping testing at the 2008 European football championship. Drug Test Anal 2009;1:485-93.

22 World Anti-Doping Agency. Minimum required performance levels for detection and identification of non-threshold substances version 1.0 (TD2013MRPL). 2012. https:// wada-main-prod.s3.amazonaws.com/resources/files/WADA-TD2013MRPL-MinimumRequired-Performance-Levels-v1-2012-EN.pdf (accessed 30 Jan 2015).

23 Kuuranne T, Saugy M, Baume N. Confounding factors and genetic polymorphism in the evaluation of individual steroid profiling. Br J Sports Med 2014;48: $848-55$.

24 de la Torre R, de la Torre X, Alia C, et al. Changes in androgenic steroid profile due to urine contamination by microorganisms: a prospective study in the context of doping control. Anal Biochem 2001;289:116-23.

25 Guddat S, Fussholler G, Geyer H, et al. Clenbuterol—regional food contamination a possible source for inadvertent doping in sports. Drug Test Anal 2012;4: 534-8.

26 Krumbholz A, Anielski P, Gfrerer L, et al. Statistical significance of hair analysis of clenbuterol to discriminate therapeutic use from contamination. Drug Test Anal 2014;6:1108-16

27 Thevis M, Geyer L, Geyer $\mathrm{H}$, et al. Adverse analytical findings with clenbuterol among U-17 soccer players attributed to food contamination issues. Drug Test Anal 2013;5:372-6.

28 Thevis $M$, Thomas A, Beuck S, et al. Does the analysis of the enantiomeric composition of clenbuterol in human urine enable the differentiation of illicit clenbuterol administration from food contamination in sports drug testing? Rapid Commun Mass Spectrom 2013;27:507-12.

29 Brodie AM, Longcope C. Inhibition of peripheral aromatization by aromatase inhibitors, 4-hydroxy- and 4-acetoxy-androstene-3,17-dione. Endocrinology 1980;106:19-21.

30 Piper T, Fussholler G, Emery $C$, et al. Investigations on carbon isotope ratios and concentrations of urinary formestane. Drug Test Anal 2012;4:942-50.

31 Cawley AT, Trout GJ, Kazlauskas R, et al. The detection of androstenedione abuse in sport: a mass spectrometry strategy to identify the 4-hydroxyandrostenedione metabolite. Rapid Commun Mass Spectrom 2008:22:4147-57.

32 World Anti-Doping Agency. The World Anti-Doping Code, the 2014 Prohibited List, International Standard. 2014. http://www.wada-ama.org/Documents/World_AntiDoping_Program/WADP-Prohibited-list/2014/WADA-prohibited-list-2014-EN.pdf (accessed 27 Feb 2014).

33 World Anti-Doping Agency. The World Anti-Doping Code: International Standard Therapeutic Use Exemptions. 2015. https://wada-main-prod.s3.amazonaws.com/ resources/files/WADA-2015-ISTUE-Final-EN.pdf (accessed 30 Jan 2015).

34 World Anti-Doping Agency. World Anti-Doping Progam, Guidelines, Reporting \& Management of human chorionic gonadotrophin (hCG) findings. 2011. https:// wada-main-prod.s3.amazonaws.com/resources/files/WADA_Guidelines_Reporting Management_hCG_findings_v1.0_EN.pdf (accessed 30 Jan 2015).

35 Goebel C. Stimulating luteinizing hormone. Drug Test Anal 2011;3: 868-72.

36 Handelsman DJ, Goebel C, Idan A, et al. Effects of recombinant human LH and hCG on serum and urine LH and androgens in men. Clin Endocrinol (Oxf) 2009:71:417-28

37 Ayotte C. Detecting the administration of endogenous anabolic androgenic steroids. Handb Exp Pharmacol 2010:77-98.

38 Sottas PE, Baume N, Saudan C, et al. Bayesian detection of abnormal values in longitudinal biomarkers with an application to T/E ratio. Biostatistics 2007:8:285-96.

39 Anielski P, Simmchen J, Wassill L, et al. Epidemiological investigation of the UGT2B17 polymorphism in doping control urine samples and its correlation to T/E ratios. Drug Test Anal 2011;3:645-51.

40 Okano M, Ueda T, Nishitani Y, et al. UDP-glucuronosyltransferase 2 B17 genotyping in Japanese athletes and evaluation of the current sports drug testing for detecting testosterone misuse. Drug Test Anal 2013;5:166-81.

41 Schulze JJ, Lundmark J, Garle M, et al. Doping test results dependent on genotype of uridine diphospho-glucuronosyl transferase 2B17, the major enzyme for testosterone glucuronidation. J Clin Endocrinol Metab 2008;93:2500-6. 


\section{Original article}

42 Jakobsson J, Ekstrom L, Inotsume $\mathrm{N}$, et al. Large differences in testosterone excretion in Korean and Swedish men are strongly associated with a UDPglucuronosyl transferase 2B17 polymorphism. J Clin Endocrinol Metab 2006;91:687-93.

43 Strahm E, Sottas PE, Schweizer C, et al. Steroid profiles of professional soccer players: an international comparative study. Br J Sports Med 2009;43:1126-30.

44 Catlin DH, Hatton CK, Starcevic SH. Issues in detecting abuse of xenobiotic anabolic steroids and testosterone by analysis of athletes' urine. Clin Chem 1997:43:1280-8
45 Cowan DA, Kicman AT. Doping in sport: misuse, analytical tests, and legal aspects. Clin Chem 1997;43:1110-13.

46 Donike M. Steroid profile in cologne. Proceedings of the 10th Manfred Donike Workshop on Dope Analysis 1992. 1993:47.

47 Donike M, Barwald KR, Klostermann K, et al. Nachweis von exogenem Testosteron [Detection of exogenous testosterone]. Sport: Leistung und Gesundheit, 1983:293-8.

48 Sottas PE, Vernec A. Current implementation and future of the athlete biological passport. Bioanalysis 2012:4:1645-52.

49 Mareck U, Geyer H, Opfermann G, et al. Factors influencing the steroid profile in doping control analysis. J Mass Spectrom 2008;43:877-91. 